Cossa: Ueber neutrale Silze des Didymoxyds etc. 383 von einer Lücke, die sein Tod gerissen, füglich nicht die Rede sein, eben so wenig, wie wir in ihm einen „Riesen der Chemie" erblicken.

Die Dumas von A. W. Hofmann gespendeten Lobpreisungen sind übertrieben, schiessen weit über das Ziel hinaus, thun dadurch seinem Ansehen Schaden.

Wenn ich das Wort wiederhole: „De mortuis nil nisi bene", so geschieht das natürlich mit dem Vorbehalte: „sed non nimis" d. h. "Maasshaiten im Lob, sich dabei nicht zu sehr von der Wahrheit entfernen"!

Leipzig, 20. Mai 1884.

H. Kolbe.

\title{
Ueber neutrale Salze des Didymoxyds und über die Valenz des Didyms;
}

von

\section{A. Cossa. ${ }^{1}$ )}

Das vor einigen Jahren von dem Verf. untersichte wolframsaure Didymoxyd erwies sich isomorph mit dem wolframsauren Kalk; diese Thatsache, sowie die, dass sich der Kalk des letzteren partiell ·durch Didymoxyd ohne Aenderung der Krystallform ersetzen lässt, führt zu der Ansicht, das wolframsaure Didymoxyd sei dem Kalksalz analog zusammengesetzt, das Didym demnach ein zweiwerthiges Metall, wie das Calcium. Dem gegenüber steht die jetzt fast allgemein adoptirte Annahme, dass Didymoxyd nach der Formel $\mathrm{Di}_{2} \mathrm{O}_{3}$ zusammengesetzt sei, welche Annahme durch Beobachtungen über die specifische Wärme des Didyms gestützt wird.

1) Auszug aus Compt. rend. 98, 990. 
384 Cossa: Ueber neutrale Salze des Didymoxyds etc.

Molybdänsaures Didymoxyd, durch Vermischen der Lösungen von salpetersaurem Didymoxyd und von neutralem molybdänsauren Natron als amoipher Niederschlag gewonnen, lässt sich durch Schmelzen bei hoher Temperatur und nachheriges Erstarren in gut ausgebildeten Krystallen erhalten, welche, sorgfältig gemessen, sich als isomorph mit natürlichem molybdänsauren Blei erwiesen. Auch in letzterem lässt sich ein Theil des Bleies durch Didym ohne Aenderung der Krystallgestalt ersetzen, so dass für beide Salze die analoge Zusammensetzung: $\mathrm{MoO}_{4} \mathrm{Di}$ und $\mathrm{MoO}_{4} \mathrm{~Pb}$ wahrscheinlich ist.

Die Entscheidung der Frage, ob Didym als zwei- oder als dreiwerthiges Element in seinen Verbindungen fungirt, wird sich definitiv erst geben lassen, wenn es - wie neuerdings beim Beryllium - gelingt, die Dampfdichte einer Didymverbindung zu bestimmen. 